\title{
Power Flow Analysis of RDS by Artificial Network Technique
}

\author{
Vaishali Holkar ${ }^{1}$, Dr. Deepika Masand ${ }^{2}$ \\ ${ }^{1}$ (Department of Electrical and Electronics Engineering, Oriental Institute of Science and \\ Technology, R.G.P.V., Bhopal(M.P.), India) \\ ${ }^{2}$ (Head of Department of Electrical and Electronics Engineering, Oriental Institute of Science and \\ Technology, R.G.P.V., Bhopal (M.P.), India)
}

\begin{abstract}
This paper shows an application of Artificial Network Technique for the analysis of load flow and determines the power system static states that is, bus voltages magnitudes and voltage angles of a balanced radial distribution system, without executing the power flow algorithm, for any given load. As the performance of the conventional load flow methods such as Fast decoupled load flow, Newton-Raphson load flow is found to be very poor under critical conditions such as high $R / X$ ratio, heavily loading condition etc. The proposed method makes use of a multi-layer feed forward ANN with error back propagation learning algorithm. The effectiveness of the proposed ANN-BPN based approach is tested by sample IEEE 33-bus, indicating its viability for RDS load flow assessment and results are presented.
\end{abstract}

Keywords: ANN-BPN, Artificial Intelligence, forward-backward sweep, ladder Iterative Technique, power flow analysis.

\section{INTRODUCTION}

Power flow or load flow studies are performed for the determination of the steady state operating condition of a power system, the solution of which gives static load flow equation that are represented mathematically by a set of non-linear algebraic equations for a given network. These is the most frequently carried out study by power utilities and are required to be performed for power system planning, operation, optimization and control. The main objective of loaf flow studies is to determine the bus voltage magnitude with its phase angle, real and reactive power flow in different lines and the transmission power losses. The paramount importance in a modern power system of fast security assessment to provide secure and reliable electrical power supply to its customers. To perform the contingency screening, which is one of the most CPU time- consuming tasks for on-line security assessment, the computation in few minutes of many load flow scenarios is required simulating the occurrence of several contingencies and different loading conditions [1].

Almost all well known methods of numerical analysis for solving a set of non-linear algebraic equations have been applied in developing load flow algorithms, during last four decades. The most desirable features to compare the different load flow methods can be the memory storage requirement, speed of solution, accuracy of the solution and the reliability of convergence depending upon a given situation.

In the recent years, with the evident of artificial intelligence- pattern recognition, decision tree, neural networks and fuzzy logic methodologies have been applied to the security assessment problem. Amongst these approaches, the applications of artificial neural networks (ANNs) have shown great promises in power system.

The ANN-BPN have been considered to be popular in power system studies and is proposed in this paper, due to the fact that a well trained ANNs can instantly recall the output for an untrained set of inputs without going through the laborious iteration procedure. Actual experimentation or by well proved standard algorithms can give the training data for an ANN. Here, the input load patterns for ANN-BPN are generated by a conventional method, 'Ladder iterative technique' which makes use of kirchoff's current law (KCL) and kirchoff's voltage law (KVL) based forward-backward sweep. The load flow solution thus obtained is used to train the neural network in MATLAB 7.0 NN tool box. The training time required is less. An implementation of BPN for determining bus voltages and the corresponding angles is been shown, followed by the results of a sample IEEE test system studied by the proposed method.

\section{LADDER ITERATIVE TECHNIQUE}

It is assumed that the ladder network parameters for lines, loads and substation voltage VS are known. If the line impedances, rated voltage and the complex power at each node are known then the values of the current, voltage, active and reactive power can be calculated using these called ladder iterative technique [12]. Iteration of the ladder iterative technique exists of two steps: forward sweep and backward sweep.

IEEE-distribution grid calculation is done as follows:

1.1. Forward sweep: 
- Assume rated voltage VS at the end node voltage $\left(\mathrm{V}_{(18)}, \mathrm{V}_{(22),}, \mathrm{V}_{(25)}, \mathrm{V}_{(33)}\right)$ is $12660+\mathrm{j} 0$ (for first iteration only) and equals the value computed in the backward sweep in the subsequent iteration.

- Start with the end node 33 and compute the node current $\mathrm{Ii}=(\mathrm{Si} / \mathrm{Vi})^{*}$. Apply the Kirchhoff's current law to determine the current flowing from node 32 towards node 33: $\mathrm{I}_{(32,33)}=\mathrm{I}_{(33)}=\left(\mathrm{S}_{(33)} / \mathrm{V}_{(33)}\right)^{*}$.

- Compute with this current the voltage, $\mathrm{V}_{(32)}=\mathrm{V}_{(33)}+\mathrm{Z}_{(32,33)} \mathrm{I}_{(32,33)}$

- $\quad$.....

- Compute with this current the voltage, $\mathrm{V}_{(6)}^{\prime}=\mathrm{V}_{(26)}+\mathrm{Z}_{(6,26)} \mathrm{I}_{(6,26)}$. This will be referred to as "the most recent voltage at node 6".

- Compute with the most recent voltage $\left(\mathrm{V}^{\prime}{ }_{(6)}\right)$ at node 6 the current $\mathrm{I}_{(6)}=\left(\mathrm{S}_{(6)} / \mathrm{V}_{(6)}\right)$ *. Apply the Kirchhoff's current law to determine the current, $I_{(5,6)}=I_{(6,7)}+I_{(6,26)}+I_{(6)}$.

- Similarly compute till the junction node.

- Using the current $\mathrm{I}_{(1,2)}$ compute the voltage, $\mathrm{V}_{(1)}=\mathrm{V}_{(2)}+\mathrm{Z}_{(1,2)} \mathrm{I}_{(1,2)}$.

At the end of the forward sweep compare the calculated magnitude of the rated voltage at node 1 to the specified source voltage.

Voltage Difference (VD) $=\left\|\mathrm{Vs}|-| \mathrm{V}_{1}\right\|$

Stop if the VD is less than a specified tolerance i.e., if $\mathrm{VD}<0.001 \mathrm{pu}(\approx 12 \mathrm{~V})$ else the backward sweep begins. The backward sweep begins at the node 1 with the rated voltage $V_{S}=V_{1}=12660+j 0$ Volts.

\subsection{Backward sweep:}

- Start with node 1 and $\mathrm{V}_{(1)}=\mathrm{V}_{(\mathrm{S})}$.

- $\quad$ Compute the voltage $\mathrm{V}_{(2)}=\mathrm{V}_{(1)}-\mathrm{Z}_{(1,2)} \mathrm{I}_{(1,2)}$.

- $\quad$.....

- $\quad$ Compute the voltage $\mathrm{V}_{(33)}=\mathrm{V}_{(32)}-\mathrm{Z}_{(32,33)} \mathrm{I}_{(32,33)}$.

After the backward sweep the first iteration is completed. At this point the forward sweep will be repeated, only this time starting with the new voltage at end nodes. These steps will be repeated until the error is less than the specified tolerance. At the substation the voltage is mostly taken 5\% bigger than the rated voltage. The key to understanding the forward and backward sweep method is that:

- The forward sweep is simply obtaining estimates of currents in each of the segments. In the forward sweep, voltage accuracy is not important.

- The backward sweep is concerned with accuracy of resulting voltages.

\section{ARTIFICIAL NEURAL NETWORK-BPN TECHNIQUE}

The most widely used learning algorithm in an ANN, the Back-propagation algorithm is presented in this context. The neural network structure defines its structure including number of hidden layers, number of hidden nodes and number of output nodes (Fig-3). Fig-4 shows the architecture of BPN to have three layers, namely- input, hidden and the output layers.

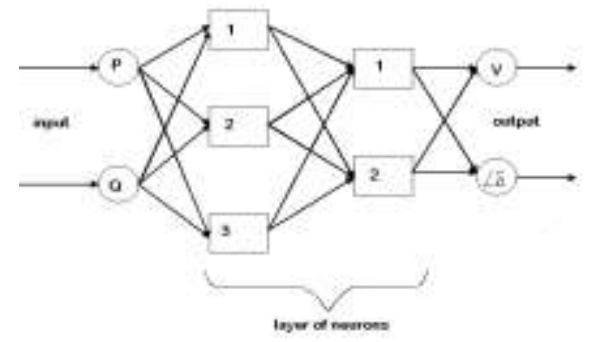

Fig.-3 Neural Network

The Multilayered Perceptron (MLP) network is trained using one of the supervised learning algorithms of which the best. It uses the data to adjust the network's weights and thresholds so as to minimize the error in its predictions on the training set. Many different sets of the input and their corresponding output vectors are considered during the training. To determine the weights between the input, hidden and output layers, the training phase is used. 


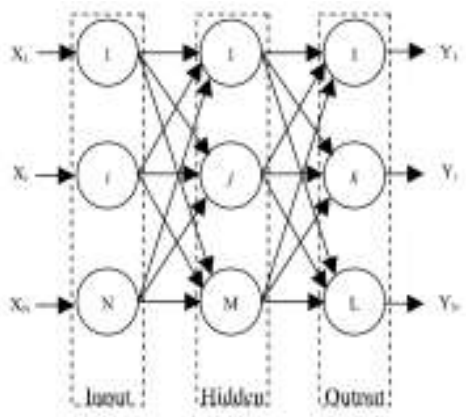

Fig.4. Basic BPN Architecture

Typically in this study neurons used are the sigmoid activation function defined by the below equation:

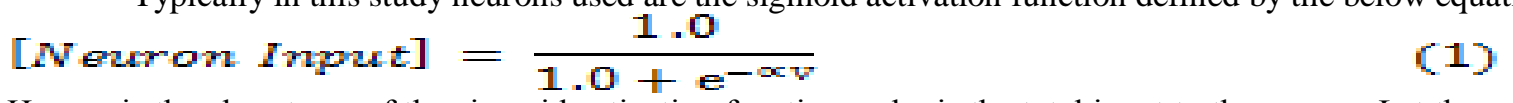

Here, $\alpha$ is the abruptness of the sigmoid activation function and $v$ is the total input to the neuron. Let the vector $\mathrm{X}$ represent an input layer as in Fig.4.The net input at the hidden layers is computed by the matrix equation below:

$$
\mathrm{V}_{\mathrm{H}}=[\mathrm{WH}] \mathrm{X}
$$

Where WHji denotes the weight between $\mathrm{i}^{\text {th }}$ input layer node and $\mathrm{j}^{\text {th }}$ hidden layer node. The output of the hidden layer node is given by,

$$
\mathrm{Y}_{\mathrm{H}}=\square\left(\mathrm{V}_{\mathrm{H}}\right)
$$

Here $\square$ is the appropriate activation function. In a similar manner the total input at the output layer is given by the following equation:

The output of the output layer node is given by,

$$
\mathrm{Vo}=[\mathrm{WO}] \mathrm{V}_{\mathrm{H}}
$$

$\mathrm{Y}=\square\left(\mathrm{V}_{\mathrm{O}}\right)$

The steps of the well set training algorithm utilizing Network's steepest descent technique are as given below:

1. Read the training set and randomly initialize the weights. Set iteration index $n=1$.

2. Set training set index $\mathrm{p}=1$.

3. Propagate $\mathrm{X}^{\mathrm{P}}$ through the network.

4. Determine the error vector of the $\mathrm{p}^{\text {th }}$ training set, $\mathrm{Ep}=\mathrm{Op}-\mathrm{Yp}$, Where Op is the vector of expected output.

5. Correct the weights using Newton's steepest descent technique.

6. If $\mathrm{p}<$ number training sets $\mathrm{P}$, set $\mathrm{p}=\mathrm{p}+1$ and go to step-3.

7. If $\sum_{p=x}^{P} \mid E^{p} \|^{p}>$ tolerance $C$, increment the iteration index $\mathrm{n}$ and go to step- 2 .

The above method explained is tested successfully and requires the input and output to be from a continuous domain. Moreover, the input and the output set of vectors are non-contradictory for a successful training and operational function.

\section{ANN-BPN IMPLEMENTATION FOR DETERMINING POWER FLOW SOLUTION}

The input vector for the ANN-BPN is the reap power and reactive power loads at various buses of power system. Therefore,

$\mathrm{X}=\left[\mathrm{P}_{1}, \mathrm{P}_{2}, \mathrm{P}_{3}, \ldots \ldots \ldots \mathrm{P}_{\mathrm{n}} ; \mathrm{Q}_{1}, \mathrm{Q}_{2}, \mathrm{Q}_{3} \ldots \ldots . . \mathrm{Q}_{\mathrm{n}}\right]$

Here, $P_{i}$ and $Q_{i}$ are the real and reactive power loads at the ith bus of the RDS and ' $n$ ' is the number of buses in the RDS.

By using this scheme several sets of loads were created:

1. By varying real and reactive power loads simultaneously at all load buses of RDS.

2. By varying both the real and reactive power loads simultaneously at a single load bus of the RDS

3. By varying only the real power load at a single load bus of the RDS.

4. By only varying the reactive power load at single load bus of the RDS.

The $\mathrm{k}^{\text {th }}$ such load so generated is referred to by the vector $\mathrm{X}^{\mathrm{k}}$. Similarly the corresponding output vector for kth input referred to $\mathrm{O}^{\mathrm{k}}$. the output vector refers to the bus voltages magnitude and the corresponding angle. Summarizing, several of these sets of input and output vectors are generated using the above method and are stored. After the successful training of the ANN-BPN it should be able to produce the bus voltage magnitude and phase angle for any of the input load pattern with maximum accuracy and minimum time.

The next section, the application of the analysis and the results of the proposed technique of determining load flow solution is discussed. 


\section{RESULT OF THE SYSTEM STUDY}

The proposed approach has been tested for 33 bus radial distribution system (Fig.5) using MATLAB environment. By using the Ladder Iterative Technique as explained in section II, the power flow equations were solved. Approximately 150 input and output vector pairs were generated for considering 33-bus system, in order to achieve a broad representation of the power system in the ANN-BPN. The BPN was trained and the results are as shown in fig.6. and the output voltages of BPN can be seen in fig.7.

And hence, the ANN-BPN is ready to use. The results from the actual load flow solution and from the training ANN for a particular pattern is shown in Table I. the method seems to be fast and found to be very efficient. It works well and smooth.

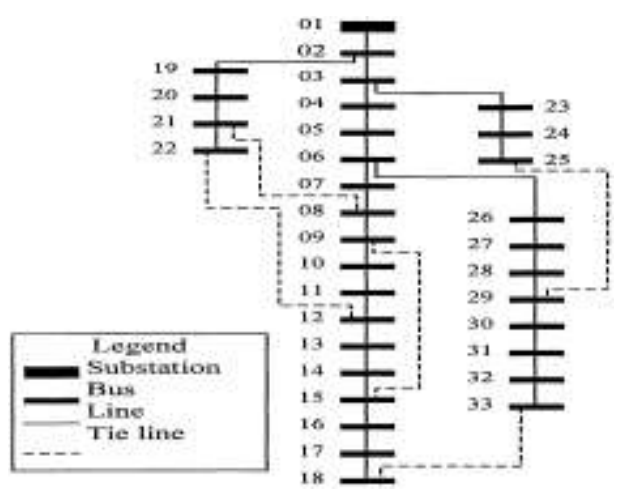

Fig.5. BPN Voltage magnitudes after training

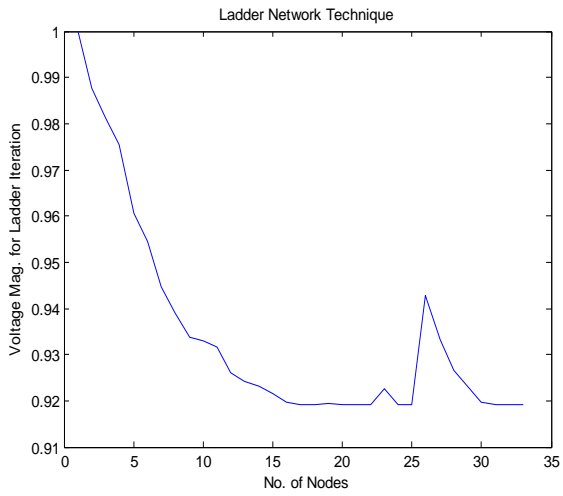

Fig.6.Ladder Iterative Voltage magnitude

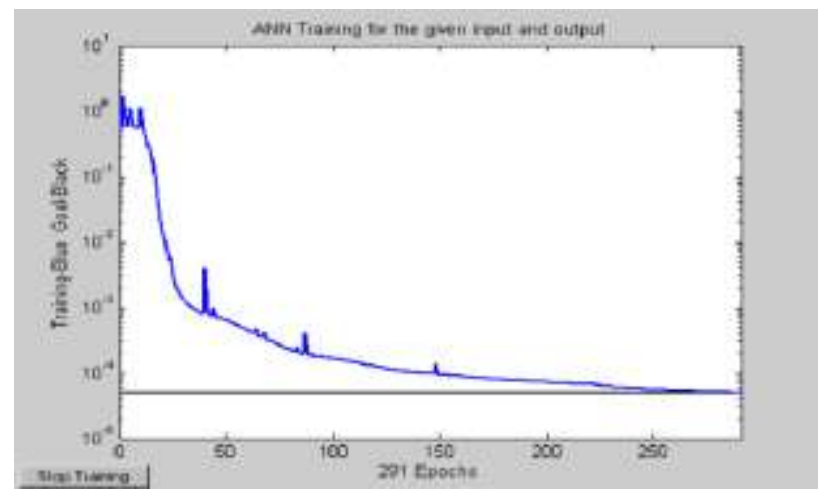

Fig. 7: Training results ANN-BPN

\section{CONCLUSION}

The novel approach in this paper presents a well defined technique to determine the load flow solution of a radial distribution system, which is simple to implement and efficient in computation. Several load pairs were considered and their solution was assessed using the conventional method of Ladder Iterative technique. Then using these pairs of input and target vector sets, the ANN-Backpropagation Network is trained. Thereafter, the BPN is ready for use wherein, given a load, it gives out the voltage solution in minimum time and maximum accuracy. The proposed reconfiguration method is tested on the standard 33-bus RDS and results demonstrate the effectiveness of the proposed method.

\section{REFERENCES}

[1] Weerasooriya S., EL-Sharkawi M., Damborg M and Marks R.J. II, Towards static security assessment of large scale power system using neural networks, IEE Porc.-C, vol. 139,1992,pp. 64-70.

[2] Stott B., Review of load flow calculation method. IEEE Proc., Vol.62, 1974,pp.916-929.

[3] W.H. Kersting and D.L.Mendive, An Applicatin of ladder network theory to the solution of three phase radial load flow problem, IEEE PES winter meeting, New Work, Jan.1976.

[4] W.H. Kersting, A method to design and operation of distribution system, IEEE Trans. Power App. Syst., vol. 103, pp. 1945$1952,1984$.

[5] R.A. Stevens, D.T.Rizy, and S.L. Puruker, Performance of conventional power flow routines for real time distribution automation application, Proc. Of 18th Southeastern Symp. On System Theory,(IEEE computer society), pp. 196-200,1986.

[6] K.Vinoth Kumar,M.P. Selvan,. A Simplified Approach for Load Flow Analysis of Radial Distribution Network, IJCIE 2:4 2008 
[7] D. Rajicic, Y. Tamura, A modification to fast decoupled power flow for networks with high R/X ratios, IEEE Trans. on Power System, Vol. 3, No. 2, pp.743-746, 1988.

[8] D. Shirmohammadi, H. W. Hong, A. Semlyen, G. X. Luo, A compensation based power flow method for weakly meshed distribution and transmission networks, IEEE Trans. on Power Systems, Vol. 3, No.2, pp.753-762, 1988.

[9] J. Padhye, V. Firoiu, and D. Towsley, A stochastic model of TCP Reno congestion avoidance and control," Univ. of Massachu setts, Amherst, MA, CMPSCI Tech. Rep. 99-02, 1999.

[10] W. H. Kersting, D. L. Mendive, An application of ladder network theory to the solution of three phase radial load flow problem IEEE PES winter meeting, New York, Jan. 1976.

[11] R. A. Stevens, D. T. Rizy, S. L. Purucker, Performance of conventional power flow routines for real time distribution automation application ,Proceedings of 18th southeastern symposium on system theory, pp.196-200, April 1986.

[12] S. Ghosh., D. Das, Method for load flow solution of radial distribution network, IEE Proc.- Gener. Transm. Distrib. Vol. 146, No. 6, pp.641-648, 1999.

[13] Radial Test Feeders- IEEE Distribution System Analysis Subcommittee accessed Septembe r2007, http://www.ewh.ieee.org/soc/pes/dsacom/testfeeders.html..

Table. 1: Results of IEEE-33 bus from conventional \& ANN-BPN method

\begin{tabular}{|c|c|c|c|c|c|c|c|c|c|}
\hline \multirow{2}{*}{$\begin{array}{l}\text { Line } \\
\text { No. }\end{array}$} & \multirow{2}{*}{$\begin{array}{c}\text { Sending } \\
\text { Bus }\end{array}$} & \multirow{2}{*}{$\begin{array}{l}\text { Receiving } \\
\text { Bus }\end{array}$} & \multicolumn{2}{|c|}{$\begin{array}{l}\text { Load at receiving } \\
\text { End Bus } \\
\text { (Test Input) }\end{array}$} & \multicolumn{2}{|c|}{ Solution From BPN } & \multicolumn{2}{|c|}{$\begin{array}{c}\text { Expected Solution } \\
\text { (Solution from } \\
\text { Ladder Iterative } \\
\text { techniaue) }\end{array}$} & \multirow{2}{*}{$\begin{array}{c}\text { Accuracy } \\
(\%)\end{array}$} \\
\hline & & & $\begin{array}{c}\text { Real } \\
\text { Power }(\mathbf{P}) \\
(\mathbf{k W})\end{array}$ & $\begin{array}{c}\text { Reactive } \\
\text { power } \\
(\mathbf{Q})\end{array}$ & $\begin{array}{c}\text { Voltage } \\
\text { Mag. } \\
\text { (pu) }\end{array}$ & $\begin{array}{l}\text { Phase } \\
\text { Angle } \\
\text { (rads) }\end{array}$ & $\begin{array}{l}\text { Voltage } \\
\text { Mag. } \\
\text { (pu) }\end{array}$ & $\begin{array}{l}\text { Phase } \\
\text { Angle } \\
\text { (rads) }\end{array}$ & \\
\hline 1 & $\begin{array}{c}1 \\
\text { Main SS }\end{array}$ & 2 & 100 & 60 & 1.00 & 0.00 & 1.00 & 0.00 & 100 \\
\hline 2 & 2 & 3 & 90 & 40 & 0.99 & 0.00 & 0.99 & 0.00 & 99.99 \\
\hline 3 & 3 & 4 & 120 & 80 & 0.98 & 0.01 & 0.98 & 0.01 & 99.98 \\
\hline 4 & 4 & 5 & 60 & 30 & 0.96 & 0.01 & 0.96 & 0.01 & 99.91 \\
\hline 5 & 5 & 6 & 60 & 20 & 0.95 & 0.02 & 0.95 & 0.02 & 99.87 \\
\hline 6 & 6 & 7 & 200 & 100 & 0.95 & 0.02 & 0.95 & 0.02 & 99.92 \\
\hline 7 & 7 & 8 & 200 & 100 & 0.93 & 0.01 & 0.93 & 0.01 & 99.61 \\
\hline 8 & 8 & 9 & 60 & 20 & 0.92 & 0.01 & 0.92 & 0.01 & 99.97 \\
\hline 9 & 9 & 10 & 60 & 20 & 0.92 & 0.01 & 0.92 & 0.01 & 99.68 \\
\hline 10 & 10 & 11 & 45 & 30 & 0.91 & 0.01 & 0.91 & 0.01 & 99.23 \\
\hline 11 & 11 & 12 & 60 & 35 & 0.91 & 0.01 & 0.91 & 0.01 & 99.47 \\
\hline 12 & 12 & 13 & 60 & 35 & 0.92 & 0.01 & 0.92 & 0.01 & 99.36 \\
\hline 13 & 13 & 14 & 120 & 80 & 0.92 & 0.01 & 0.92 & 0.01 & 99.24 \\
\hline 14 & 14 & 15 & 60 & 10 & 0.92 & 0.01 & 0.92 & 0.01 & 99.23 \\
\hline 15 & 15 & 16 & 60 & 20 & 0.92 & 0.01 & 0.92 & 0.01 & 99.15 \\
\hline 16 & 16 & 17 & 60 & 20 & 0.92 & 0.01 & 0.92 & 0.01 & 99.58 \\
\hline 17 & 17 & 18 & 90 & 40 & 0.92 & 0.01 & 0.92 & 0.01 & 99.78 \\
\hline 18 & 2 & 19 & 90 & 40 & 0.92 & 0.01 & 0.92 & 0.01 & 99.14 \\
\hline 19 & 19 & 20 & 90 & 40 & 0.92 & 0.00 & 0.92 & 0.00 & 99.55 \\
\hline 20 & 20 & 21 & 90 & 40 & 0.90 & 0.00 & 0.90 & 0.00 & 99.59 \\
\hline 21 & 21 & 22 & 90 & 40 & 0.90 & 0.00 & 0.90 & 0.00 & 99.95 \\
\hline 22 & 3 & 23 & 90 & 50 & 0.90 & 0.00 & 0.90 & 0.00 & 99.87 \\
\hline 23 & 23 & 24 & 420 & 200 & 0.99 & 0.00 & 0.99 & 0.00 & 99.99 \\
\hline 24 & 24 & 25 & 420 & 200 & 0.99 & 0.00 & 0.99 & 0.00 & 99.91 \\
\hline 25 & 6 & 26 & 60 & 25 & 0.99 & 0.00 & 0.99 & 0.00 & 99.71 \\
\hline 26 & 26 & 27 & 60 & 25 & 0.98 & 0.02 & 0.98 & 0.02 & 99.32 \\
\hline 27 & 27 & 28 & 60 & 20 & 0.97 & 0.02 & 0.97 & 0.02 & 99.33 \\
\hline 28 & 28 & 29 & 120 & 70 & 0.96 & 0.02 & 0.96 & 0.02 & 99.27 \\
\hline 29 & 29 & 30 & 200 & 600 & 0.94 & 0.02 & 0.94 & 0.02 & 99.71 \\
\hline 30 & 30 & 31 & 150 & 70 & 0.93 & 0.03 & 0.93 & 0.03 & 99.71 \\
\hline 31 & 31 & 32 & 210 & 100 & 0.92 & 0.03 & 0.92 & 0.03 & 99.19 \\
\hline 32 & 32 & 33 & 60 & 40 & 0.92 & 0.02 & 0.91 & 0.02 & 98.71 \\
\hline & & & & ubsta & age $=12$ & & & & \\
\hline
\end{tabular}

